\title{
BIOMETRIA, DORMÊNCIA E VIABILIDADE DE SEMENTES DE SENNA MACRANTHERA
}

\author{
LOPES, José Carlos ${ }^{1}$ \\ BARBOSA, Luciana Gomes ${ }^{2}$ \\ CAPUCHO, Marilda Torres ${ }^{1}$
}

\begin{abstract}
RESUMO: Objetivou-se no presente trabalho estudar a biometria, dormência e viabilidade de sementes de Senna macranthera. O estudo foi conduzido no Laboratório de Sementes do Centro de Ciências Agrárias da Universidade Federal do Espírito Santo (CCA-UFES), e na Fazenda Tecnotruta, na Serra do Caparaó. Foram conduzidos dois experimentos em um delineamento inteiramente casualizado com quatro repetições de 25 sementes. No primeiro, os tratamentos utilizados foram: imersão em água a $70{ }^{\circ} \mathrm{C}$ por 1,2 e 3 minutos; água a $90{ }^{\circ} \mathrm{C}$ por $1,2,3,10$ e 20 minutos; água a $97{ }^{\circ} \mathrm{C}$ por 5,10 e 15 minutos; água a $97{ }^{\circ} \mathrm{C}$ até esfriar; imersão em ácido sulfúrico concentrado por 10, 15, 20, 30, 40 e 60 minutos, escarificação mecânica e sementes intactas como controle. No segundo, as sementes foram acondicionadas em embalagens de BOPP metalizadas e armazenadas em geladeira e em ambiente natural nas condições de laboratório na Serra do Caparaó. Foram avaliados germinação e vigor das sementes por 12 meses. As sementes apresentam impermeabilidade do tegumento; as escarificações mecânica e química com ácido sulfúrico são mais eficientes para superar a dormência, com porcentagem de germinação superior a 88\%; a viabilidade das sementes mantém-se inalterada em geladeira e em ambiente natural nas condições de laboratório na Serra do Caparaó por 12 meses.
\end{abstract}

Palavras-chave: Germinação. Vigor. Tegumento impermeável. Armazenamento

\section{BIOMETRICS, DORMANCY AND VIABILITY OF SENA MACRANTHERA SEEDS}

SUMMARY: With the aim of study biometry, dormancy and viability of Sena macranthera seeds. The studies were accomplished out at the Seed Laboratory from the Center of Agrarian Sciences of Federal University of Espírito Santo (CCA-UFES), and on the farm Tecnotruta, in the Serra do Caparaó. Were carried two experiments in statistical completely randomized, with four replications of 25 seeds. At first, the treatments used were: immersion in water at $70{ }^{\circ} \mathrm{C}$ for 1,2 and 3 minutes; immersion in water at $90^{\circ} \mathrm{C}$ for $1,2,3,10$ and 20 minutes; immersion in boiling water $\left(97{ }^{\circ} \mathrm{C}\right)$ to 5,10 and 15 minutes; immersion in boiling water $\left(97{ }^{\circ} \mathrm{C}\right)$ until cool; immersion in concentrated sulfuric acid (98\%) to $10,15,20,30,40$ and 60 minutes, mechanical scarification and intact seeds as control. In the second, the seeds were packed in metalized BOPP packaging and stored in the fridge and in the natural environment in laboratory conditions in the Serra do Caparaó. The germination and vigor were evaluated of 12 months. The seeds present impermeability of integument; that mechanical and chemical scarification with sulfuric acid are more efficient to overcome the dormancy, with germination percentage higher than $88 \%$; the viability of the seeds remains unchanged in the fridge and in the natural environment in a laboratory conditions in the Serra do Caparaó for 12 months.

Keywords: Germination. Vigor. Impermeability of tegument. Storage.

\section{INTRODUÇÃO}

A dormência um mecanismo que favorece a sobrevivência das espécies em relação aos fatores

\footnotetext{
${ }^{1}$ Departamento de Produção Vegetal, Programa de Pós-graduação em Produção Vegetal no Centro de Ciências Agrárias da Universidade Federal do Espírito Santo (PPGPV-CCA/UFES). CP: 16, CEP: 29500-000, Alegre - ES. email: jcufes@bol.com.br; marufes@bol.com.br.

${ }^{2}$ Universidade Federal da Paraíba, UFPB, Brasil. e-mail:1ucianabarbosa@cca.ufpb.br.
} 
adversos do ambiente. Há três tipos de dormência em sementes: dormência imposta pelo tegumento, dormência em nível de embrião (subdesenvolvido, subdiferenciado ou rudimentar) e dormência devido a substâncias promotoras e inibidoras (BEWLEY; BLACK, 1994). A ocorrência de dormência por impermeabilidade do tegumento está associada com espécies de diversas famílias botânicas, sendo mais frequente na família Leguminosae, que apresenta grande número de espécies com sementes duras, observando-se particularmente o maior contingente nas subfamílias Caesalpinoideae e Mimosoideae (LORENZI, 1992; BEWLEY; BLACK, 1994). Essas sementes que apresentam estrutura e consistência compactas e impermeáveis à água e a gases, e a inibição mecânica e química da germinação constituem o grupo de sementes denominadas sementes duras e, por este motivo não germinam nas condições naturais de campo, ou apresentam um índice baixíssimo de germinação (LORENZI, 1992; BEWLEY; BLACK, 1994; BRASIL, 2009).

A Senna macranthera, popularmente conhecida como fedegoso é uma planta da família Leguminosae-Caesalpinoideae, semidecídua ou decídua durante o inverno, heliófila, indiferente às características físicas do solo e muito frequente em formações secundárias de regiões de altitude. Devido ao porte, 6 a 8 metros de altura, e a beleza de suas flores é muito utilizada em projetos paisagísticos e na ornamentação de ruas e praças. Recomendada para plantios em áreas degradadas de preservação permanente por ser uma espécie pioneira e de rápido crescimento (LORENZI, 1992).

A maior dificuldade na propagação da Sena macranthera é atribuída ao fenômeno da dormência, com desuniformidade e baixa porcentagem de germinação das sementes, o que evidencia a necessidade estudos de métodos para superação da sua dormência. Neste sentido, vários trabalhos têm sido desenvolvidos com diversas espécies utilizando-se escarificação química, como em sementes de Caesalpinea ferrea (LOPES et al., 1998); água quente em sementes de Ormosia nítida (LOPES et al., 2006); escarificação mecânica em sementes de Adenanthera pavonina (COSTA et al., 2010); Schizolobium parahyba (PEREIRA et al., 2011).

Para a realização de trabalhos de propagação, de recomposição de paisagens degradadas por atividades extrativistas e outras exercidas pelo homem, torna-se necessário a obtenção de mudas de qualidade. A necessidade da realização de testes que visem a superação da dormência e uniformização da germinação das sementes de espécies para estes fins é, portanto, de grande importância. Assim, este trabalho teve por objetivo estudar a biometria, a curva de embebição e o melhor método para superação de dormência em sementes de Senna macranthera.

\section{MATERIAL E MÉTODOS}

O trabalho foi conduzido no Laboratório de Sementes do Centro de Ciências Agrárias da Universidade Federal do Espírito Santo (CCA-UFES), em Alegre - ES.

As sementes de Senna macranthera (Collad.) Irwin et Barn. foram coletadas manualmente em cinco árvores matrizes existentes na Fazenda Tecnotruta, no Pico da Bandeira, Serra do Caparaó, Município de Ibitirama-ES e na Fibria em Aracruz-ES, transportadas para o laboratório, onde foram beneficiadas, separadas sementes chochas, verdes e mal formadas, e posteriormente desinfestadas em álcool $70 \%$ por um minuto, seguida de três lavagens em solução de hipoclorito de sódio a $2 \%$ por 10 minutos secas à sombra por $24 \mathrm{~h}$. As sementes foram armazenadas em geladeira $3{ }^{\circ} \mathrm{C}$ e em ambiente natural nas condições de laboratório, na Fazenda Tecnotruta, Serra do Caparaó, em Ibitirama, por 12 meses, em embalagens plásticas tipo BOPP metalizada, lacradas em máquina de termossoldadora (IMEC). Posteriormente, foram realizados testes de umidade, germinação e vigor, periodicamente, durante 12 meses, sendo considerada a análise inicial como controle. 
Sementes recém-colhidas foram submetidas aos tratamentos para superação da dormência: a) escarificação mecânica por atrito da parte do tegumento oposta ao embrião, com uma lixa d'água $n^{\circ} 100$; b) imersão em água quente $\left(70{ }^{\circ} \mathrm{C}\right)$ por 1,2 e 3 minutos; c) imersão em água quente $\left(90{ }^{\circ} \mathrm{C}\right)$ por $1,2,3,10$, 20 e 30 minutos; d) imersão em água quente $\left(97{ }^{\circ} \mathrm{C}\right)$ por 5, 10 e 15 minutos; e) imersão em água quente $\left(97{ }^{0} \mathrm{C}\right)$ até esfriar; f) imersão em ácido sulfúrico $\left(\mathrm{H}_{2} \mathrm{SO}_{4}\right)$ concentrado, por 10, 15, 20, 30, 40 e 60 minutos, seguida de lavagem em água corrente, por cerca de dez minutos; e g) sementes sem tratamento (controle).

Após os tratamentos, as sementes foram submetidas aos testes e/ou determinações descritas a seguir: peso de mil sementes - para a determinação do peso de mil sementes foram utilizadas oito repetições de 25 sementes intactas, e o valor obtido calculado de acordo com Brasil (2009). Comprimento e largura das sementes - o comprimento e a largura das sementes foram obtidos com o auxílio de uma régua milimetrada, utilizando-se quatro repetições de 25 sementes, e os resultados foram expressos em mm. Curva de embebição - Para o estudo da embebição foram utilizadas três sub-amostras de 15 sementes, intactas e escarificadas, semeadas em placas de Petri, com o substrato umedecido com água destilada à temperatura constante de $30^{\circ} \mathrm{C}$, em BOD. Periodicamente, cada sub-amostra/tratamento foi pesada de hora em hora, durante oito horas, em balança com precisão de $0,001 \mathrm{~g}$, tendo-se o cuidado de retirar as sementes das placas, remover a umidade superficial das sementes com papel absorvente e pesadas. Com os dados das pesagens sucessivas foi calculada a porcentagem de ganho de água em relação ao peso inicial para o ajuste das curvas de embebição. Teor de água das sementes - foi determinado utilizando-se duas subamostras de 15 sementes, pesadas em balança com precisão de 0,001 g, em seguida colocadas em estufa a $105 \pm 3{ }^{\circ} \mathrm{C}$, durante $24 \mathrm{~h}$ (BRASIL, 2009). Os resultados foram expressos em porcentagem média (base úmida). Germinação - o teste de germinação foi conduzido com quatro subamostras de 25 sementes, colocadas em placas de Petri, sobre papel germitest umedecido com água destilada na proporção de 3,0 vezes o seu peso seco, mantidas em câmaras tipo BOD equipadas com quatro lâmpadas fluorescentes de 20 watts, com fotoperíodo de 8-16 horas, na temperatura de $30{ }^{\circ} \mathrm{C}$. As avaliações foram feitas diariamente, computando-se as sementes que apresentavam protrusão da raiz primária com dimensão $\geq 2 \mathrm{~mm}$ de comprimento. A porcentagem de germinação foi considerada a porcentagem de plântulas normais no final do teste, ou seja, que apresentavam todas as estruturas essenciais perfeitas (BRASIL, 2009). Os testes foram encerrados quando a germinação das sementes se manteve constante. Índice de velocidade de germinação (IVG) - foi conduzido concomitante com o teste de germinação, computando-se diariamente o número de sementes que apresentou protrusão da raiz primária com dimensão $\geq 2 \mathrm{~mm}$. Para o cálculo, utilizou-se a fórmula de Maguire (1962): IVE = G1/N1+ $\mathrm{G} 2 / \mathrm{N} 2+\ldots+\mathrm{Gn} / \mathrm{Nn}$, onde: $\mathrm{G} 1, \mathrm{G} 2, \ldots \mathrm{Gn}=$ número de sementes que apresentaram protrusão da raiz primária computadas na primeira, segunda até a enésima observação. $\mathrm{N} 1, \mathrm{~N} 2, \ldots \mathrm{Nn}$ = número de dias após a semeadura.

Delineamento estatístico: $O$ delineamento experimental utilizado nos dois experimentos foi $o$ inteiramente casualizado com quatro repetições de 25 sementes, sendo que no armazenamento foram dois tratamentos na parcela representados pelos ambientes de armazenamento (câmara fria e ambiente natural) e nas sub-parcelas os tempos de armazenamento (0,2, 4, 6, 8, 10 e 12 meses). Os dados foram submetidos à análise de variância e regressão polinomial, seguido da comparação de médias pelo teste de Tukey em nível de 5\% de probabilidade, utilizando-se o software SAEG. 


\section{RESULTADOS E DISCUSSÃO}

Os resultados relativos às características físicas das sementes de Senna macranthera estão agrupados na Tabela 1. O fruto é uma vagem, quando seca deiscente, conforme citado por Lorenzi (1992) contendo cerca de 45 sementes, com largura e comprimento de 0,03 e $0,04 \mathrm{~mm}$, respectivamente, com peso de mil sementes de $36 \mathrm{~g}$ e 27.500 sementes por quilograma. O peso de mil sementes, como uma característica influenciada pelo teor de água, exerce influência no número de sementes por quilo.

Tabela 1. Características físicas de sementes Senna macranthera.

\begin{tabular}{lc}
\hline Parâmetros & Valores médios \\
\hline Umidade (\%) & 11 \\
Peso de mil sementes $(\mathrm{g})$ & 36 \\
Número de sementes/kg & 27.500 \\
Largura (mm) & 0,03 \\
Comprimento (mm) & 0,04 \\
Número de sementes/fruto & 45 \\
\hline
\end{tabular}

Na Figura 1 são apresentadas as curvas de embebição das sementes recém colhidas, intactas e escarificadas em um período de oito horas. Verifica-se que nas sementes intactas não ocorreu embebição, enquanto nas escarificadas verificou-se que ocorreu absorção de água, com um aumento de peso durante as primeiras seis horas, estabilizando-se após esse período. Estes resultados sugerem que essas sementes apresentam resistência à passagem de água através do tegumento, a que se atribui o fenômeno da dormência (BEWLEY; BLACK, 1994), necessitando, portanto, de tratamentos especiais para acelerar a embebição e uniformizar a germinação, principalmente considerando que o processo e o período inicial de embebição são críticos para a germinação.

Figura 1. Curva de embebição de sementes de Senna macranthera intacta e escarificada

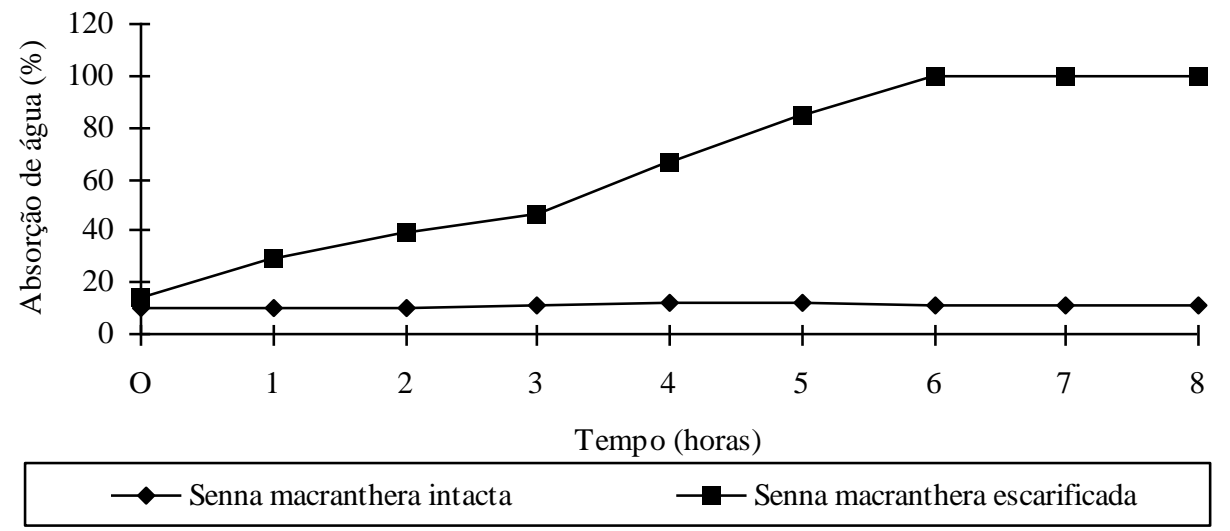

Nos tratamentos feitos com água quente (Tabela 2, Figura 2), a temperatura de $70{ }^{\circ} \mathrm{C}$ durante dois minutos determinou aumento significativo na porcentagem e na velocidade de germinação em relação ao controle. Verificou-se a o tratamento determinou o amolecimento e trincamento no tegumento, 
favorecendo a permeabilidade, mas não foi suficiente para superar totalmente a dormência das sementes. Nos demais tratamentos feitos com água quente, verificou-se que com o aumento da temperatura da água e do tempo de exposição das sementes houve redução na porcentagem de germinação, culminando com a morte do embrião. Embora tenha ocorrido amolecimento e trincamento do tegumento das sementes, possivelmente, os tratamentos feitos com temperaturas mais elevadas causaram danos nos embriões. Esses resultados mostram a eficiência de tratamentos de termoterapia em relação ao aumento da permeabilidade do tegumento, entretanto, é necessário avaliar temperaturas menos drásticas e tempos de exposição menores para não causar danos aos embriões das sementes. Resultados positivos com a utilização de água quente foram encontrados em sementes de Acacia mearnsiie (SMIDERLE et al., 2005), Schyzolobium parahyba (MATHEUS et al., 2007) e Mimosa caesalpiniifolia Benth. (LEAL et al., 2008). Entretanto, Albuquerque et al. (2007) trabalhando com sementes de sucupira-preta, verificaram que a utilização de água a $80{ }^{\circ} \mathrm{C}$ resultou em menor porcentagem e velocidade de germinação das sementes em relação aos demais tratamentos. Tratamentos feitos com temperaturas mais elevadas não foram eficientes para a superação da dormência, e culminaram com a deterioração das sementes, inibindo completamente a sua germinação. Resultados semelhantes foram encontrados por Suñé e Franke (2006) em sementes de Desmanthus depressus, com imersão em água à temperatura de $60^{\circ} \mathrm{C}$ por 5 minutos.

Figura 2. Germinação (\%) e índice de velocidade de germinação (IVG) de sementes de Senna macranthera após tratamentos com termoterapia, (A) $70{ }^{\circ} \mathrm{C}$, (B) $90{ }^{\circ} \mathrm{C}$ e (C) $100{ }^{\circ} \mathrm{C}$. Laboratório de Sementes, CCA-UFES, Alegre-ES, 2010.

A.

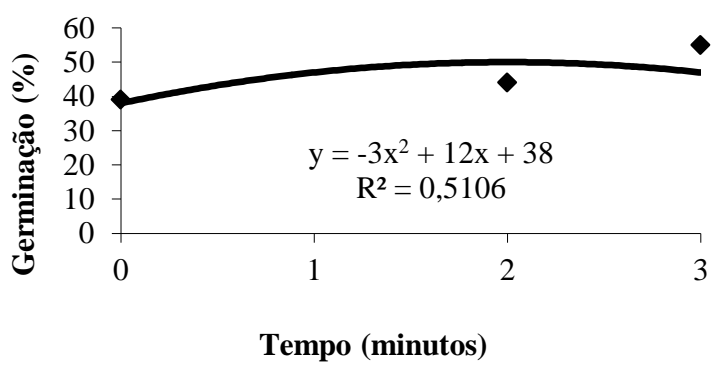

B.

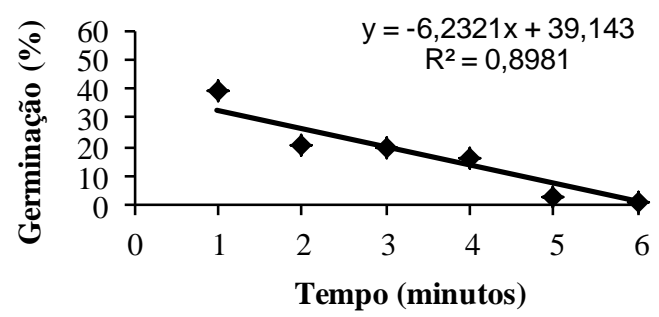

$0=$ controle $\quad 1=1^{\prime} \quad 2=2^{\prime} \quad 3=3^{\prime} \quad 4=10^{\prime} \quad 5=$ $20^{\prime} 6=30^{\prime}$
A.

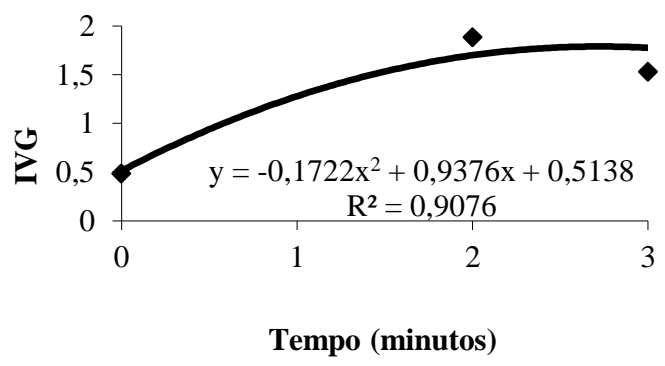

B.

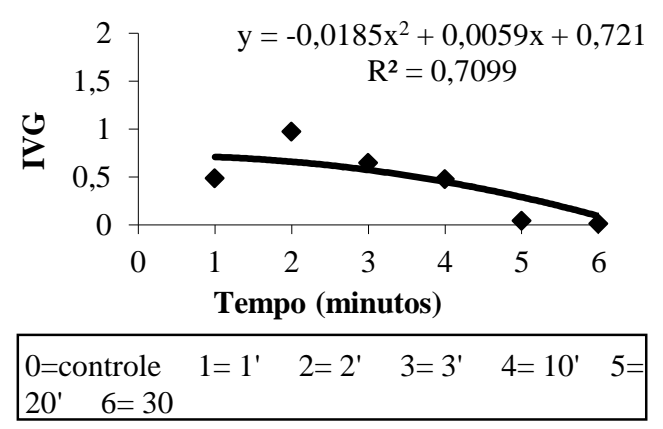


C.

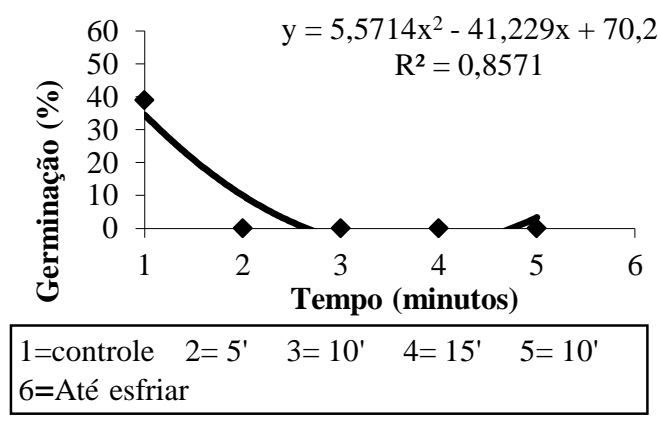

C.

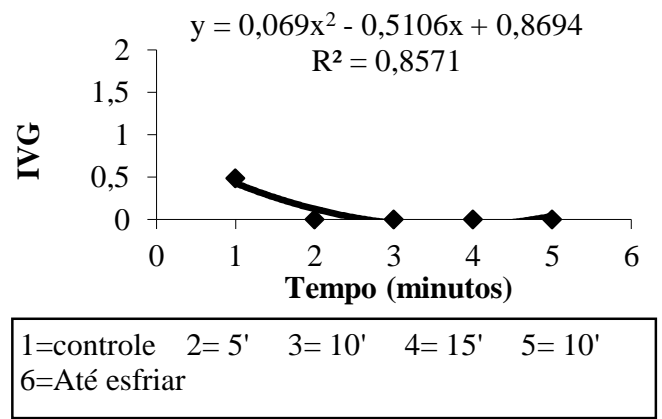

Os tratamentos feitos com escarificação ácida e mecânica (Figura 3) resultaram em porcentagem de germinação e índice de velocidade de germinação (IVG) significativamente maiores que os valores obtidos nos demais tratamentos, e não houve efeito do tempo de imersão das sementes em ácido sulfúrico, cujos resultados foram similares. Independente do tempo de imersão em ácido sulfúrico, o menor valor de germinação foi de 89\%, com índice de velocidade de germinação (IVG) de 7,18 e 6,35, com os tempos de imersão feitos por 10 e por 60 minutos, respectivamente, enquanto com a imersão por 15 minutos resultou em valores de $96 \%$ e 8,67, respectivamente, considerada como melhor expressão do vigor. Em sementes de Adenantera pavoniana, Costa et al. (2010) obtiveram 85\% de germinação com imersão em ácido sulfúrico por 5 e 10 minutos, analogamente Kismann et al. (2008) trataram sementes de Adenanthera. pavonina por imersão em ácido sulfúrico por 10 e 20 minutos e obtiveram maior germinação e expressão do vigor. Resultados semelhantes foram observados em sementes de Merremia aegyptia (PEREIRA et al., 2007). A escarificação mecânica, embora tenha determinado aumento na absorção de água durante o período de embebição (Figura 1), e na porcentagem de germinação (88\%) das sementes (Figura 2) foi o tratamento de escarificação no qual as sementes apresentaram menor expressão do vigor $(5,01)$. Pereira $e t$ al. (2011), trabalhando com métodos de escarificação em sementes de Schizolobium parahyba observaram que a escarificação mecânica com tesoura e com lixa apresentou-se como o método mais apropriado para a superação da dormência dessas sementes.

Figura 3. Germinação (\%) e índice de velocidade de germinação (IVG) de sementes de Senn macranthera após escarificação química
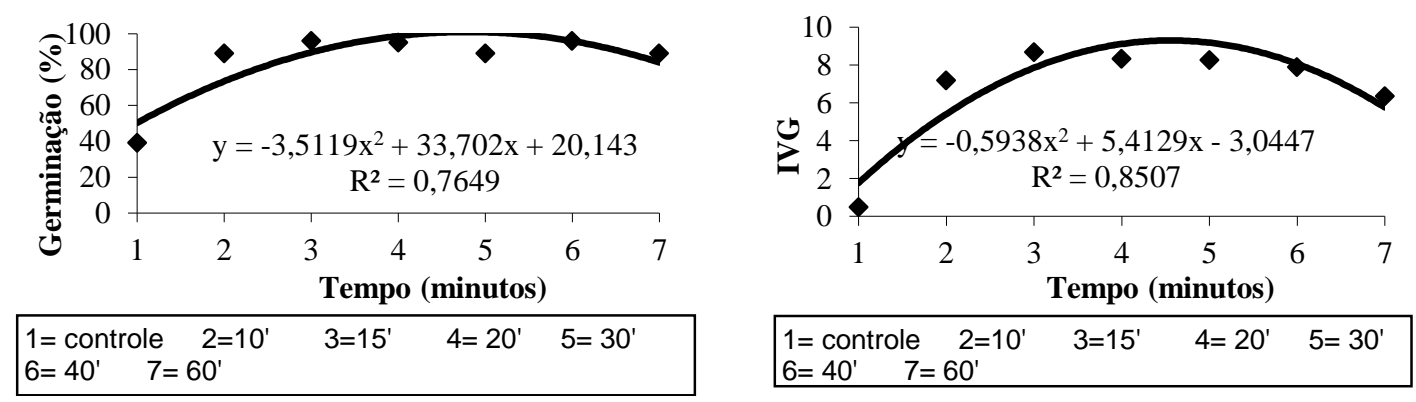

Lopes et al. (2006) observaram que todos os tratamentos utilizados na superação da dormência de sementes de Ormosia nitida apresentaram respostas positivas na percentagem e velocidade de germinação em relação ao controle. Os valores médios da germinação evidenciaram que os tratamentos feitos com 
escarificação mecânica não diferiram estatisticamente do controle e que a utilização do ácido sulfúrico, embora tenha elevado à percentagem de germinação apresentou resultados estatisticamente similares aos tratamentos com escarificação mecânica.

Embora a utilização de ácido seja um método perigoso, vários autores como Lopes et al. (1998); Smiderle et al. (2005); Albuquerque et al. (2007); Alves et al. (2007); Passos et al. (2007), Nascimento et al. (2009); Giachini et al. (2010); Costa et al. (2010); Pereira et al. (2011), também utilizaram esse método e obtiveram bons resultados na superação da dormência das sementes e conseqüente germinação. Entretanto, tratamentos das sementes com ácido sulfúrico feitos por períodos superiores aos aqui apresentados determinaram deterioração das sementes.

Com relação ao período de armazenamento das sementes, verificou-se que a germinação inicial (88\%) manteve-se praticamente inalterada por 12 meses, apresentando algumas oscilações no vigor, avaliado pelo índice de velocidade de germinação (IVG) (Tabela 2).

Tabela 2. Germinação (\%), sementes duras (\%) e índice de velocidade de germinação (IVG) de sementes de Senna macranthera após diferentes períodos e condições de armazenamento.

\begin{tabular}{|c|c|c|c|c|c|c|}
\hline \multirow[b]{2}{*}{$\begin{array}{l}\text { Armazenamento } \\
\text { (meses) }\end{array}$} & \multicolumn{2}{|c|}{$\begin{array}{c}\text { Germinação } \\
(\%)\end{array}$} & \multicolumn{2}{|c|}{$\begin{array}{c}\text { Sementes duras } \\
(\%)\end{array}$} & \multicolumn{2}{|c|}{ IVG } \\
\hline & Geladeira & $\begin{array}{c}\text { Ambiente } \\
\text { natural }\end{array}$ & Geladeira & $\begin{array}{c}\text { Ambiente } \\
\text { natural }\end{array}$ & Geladeira & $\begin{array}{c}\text { Ambiente } \\
\text { natural }\end{array}$ \\
\hline 0 & $88^{\text {ns }}$ & $88^{\text {ns }}$ & 5 & 5 & $2,04 \mathrm{~b}$ & $2,04 b$ \\
\hline 2 & $93^{\mathrm{ns}}$ & $90^{\mathrm{ns}}$ & 7 & 10 & $2,26 \mathrm{a}$ & $2,11 b$ \\
\hline 4 & $89^{\mathrm{ns}}$ & $94^{\mathrm{ns}}$ & 11 & 6 & $1,87 b$ & $2,84 a$ \\
\hline 6 & $94^{\mathrm{ns}}$ & $92^{\mathrm{ns}}$ & 6 & 8 & $2,49 a$ & $2,01 \mathrm{~b}$ \\
\hline 8 & $92^{\mathrm{ns}}$ & $93^{\mathrm{ns}}$ & 8 & 7 & $1,99 b$ & $2,65 a$ \\
\hline 10 & $93^{\text {ns }}$ & $94^{\mathrm{ns}}$ & 7 & 4 & $2,38 \mathrm{a}$ & $2,79 a$ \\
\hline 12 & $92^{\mathrm{ns}}$ & $93^{\mathrm{ns}}$ & 8 & 7 & $2,51 \mathrm{a}$ & $2,68 \mathrm{a}$ \\
\hline
\end{tabular}

Médias seguidas por uma mesma letra, não diferem estatisticamente entre si, pelo teste de Tukey, em nível de a 5\% de probabilidade.

As condições e o período em que as sementes foram armazenadas não determinaram diferenças significativas nos teores de água das sementes, que foram reduzidos para 8,45\% antes do armazenamento e mantiveram-se praticamente inalterados por 12 meses $(8,51 \pm 0,3 \%)$. A baixa oscilação no teor de água é atribuída ao tipo de embalagem utilizada, BOPP metalizada, que apresentam alta rigidez, não permitem a contaminação das sementes e oferecem resistência à passagem de gases. Entretanto, o conhecimento dos limites tolerados de perda de água pela semente auxilia na manutenção da sua qualidade fisiológica e no correto armazenamento (DAVIDE; SILVA, 2008). Com relação à germinação, verificou-se que tanto em ambiente de câmara fria como em ambiente natural nas condições de laboratório, não houve diferenças, embora com algumas oscilações, o mesmo comportamento verificado no vigor das sementes. Na avaliação dos ambientes também não se verificou diferenças na preservação da qualidade fisiológica das sementes, sugerindo um comportamento ortodoxo para esta espécie, que se comportam como tolerantes à dessecação e podem ser armazenadas com reduzido teor de água em ambientes com baixos valores de temperatura e umidade relativa do ar, de acordo com a caracterização proposta por Roberts (1973). Sementes de Acacia 
polyphylla acondicionadas em embalagens de papel e armazenadas em câmara fria mantiveram a capacidade germinativa próxima da inicial, por um período de aproximadamente um ano (ARAÚJO NETO et al., 2005). O acondicionamento de sementes de Tabebuia roseo-alba e de Tabebuia impetiginosa em lata e manutenção em geladeira é uma condição adequada para o armazenamento, sendo que sementes de T. impetiginosa também podem ser conservadas embaladas em saco de polietileno, saco de papel Kraft ou lata, quando estocadas em câmara refrigerada (BORBA FILHO; PEREZ, 2009). Em sementes de A. peregrina var. falcata e A. colubrina var. cebili, a redução na umidade e o armazenamento elas apresentam comportamento ortodoxo, mas com curta longevidade quando armazenadas em ambiente não controlado (MARQUES, 2007).

Durante o período de armazenamento, as sementes de Senna macranthera acondicionadas em embalagens de BOPP metalizada e mantidas em geladeira e em ambiente natural nas condições de ambiente de laboratório apresentaram oscilações no vigor. Essas oscilações, embora significativas, foram mínimas, e podem ser atribuídas ao fenômeno da dormência, em que no processo de escarificação, que antecedeu as análises de germinação, pode ter ocorrido menos intensidade do processo em algumas sementes, o que possivelmente prejudicou sua embebição e consequentemente a germinação.

\section{CONCLUSÃO}

Nas condições metodológicas utilizadas na condução dos experimentos, pode-se concluir que: . as sementes apresentam dormência em nível de tegumento, com baixo índice de germinação;

. a escarificação mecânica e a química com $\mathrm{H}_{2} \mathrm{SO}_{4}$ são eficientes para superar a dormência das sementes de Senna macranthera;

. a termoterapia com as temperaturas e tempos utilizados não apresentaram resultados satisfatórios na superação da dormência e germinação das sementes de Senna macranthera;

. tratamento com ácido sulfúrico concentrado por 15 minutos é eficiente para superar a dormência tegumentar em sementes de Senna macranthera;

- a viabilidade das sementes mantém-se inalterada em geladeira e em ambiente natural nas condições de laboratório por 12 meses.

\section{AGRADECIMENTOS}

Os autores agradecem ao CNPq, pelos auxílios com a concessão de bolsa de iniciação científica ao segundo autor e bolsa de apoio técnico à pesquisa a Eng ${ }^{\mathrm{a}} \mathrm{Agr}^{\mathrm{a}}$ Marilda Torres Capucho, ao laboratorista José Maria Barbosa pelo auxílio técnico e ao Eng ${ }^{\circ}$ Florestal Renato Moraes de Jesus pela cessão de sementes e ao Sr. Francisco Faleiro Lemos, Empresa Tecnotruta, Serra do Caparaó, pela cessão da área para coleta de material vegetal.

\section{REFERÊNCIAS}

ALBUQUERQUE, K.S. et al. Métodos para a superação da dormência em sementes de sucupira-preta (Bowdichia virgilioides Kunth.). Ciência e Agrotecnologia, v.31, n.6, p.1716-1721, 2007. Disponível em: http://www.scielo.br/pdf/cagro/v31n6/a17v31n6.pdf

ALVES, E.U. et al. Superação da dormência em sementes de Caesalpinia pyramidalis Tul. Revista Árvore, v.31, n.3, p.405-415, 2007. Disponível em: http://www.scielo.br/pdf/rarv/v31n3/06.pdf 
ARAÚJO NETO, J.C. et al. Armazenamento e requerimento fotoblástico de sementes de Acacia polyphylla DC. Revista Brasileira de Sementes, Pelotas, v.27, n.1, p.15-124, 2005.

www.scielo.br/pdf/rarv/v35n4/a06v35n4.pdf

BEWLEY, J.D.; BLACK, M. Seeds: physiology of development and germination. 2.ed. New York: Plenun Press, 1994. 445p.

BORBA FILHO, A.B.; PEREZ, S.C.J.G.A. Armazenamento de sementes de ipê-branco e ipê-roxo em diferentes embalagens e ambientes. Revista Brasileira de Sementes, v.31, n.1, p.259-269, 2009. Disponível em: www.scielo.br/pdf/rbs/v31n1/a29v31n1.pdf

BRASIL. Ministério da Agricultura e Reforma Agrária. Regras para análise de sementes. Brasília: Mapa/ACS. 2009. 395p.

COSTA, P.A.et al. Quebra de dormência em sementes de Adenanthera pavonina L. Pesquisa Agropecuária Tropical, v.40, n.1, p.83-88, 2010. www.revistas.ufg.br/index.php/pat/article/view/4092/6261

DAVIDE, A. C.; SILVA, E. A. A. Sementes florestais. In: DAVIDE, A.C.; SILVA, E.A.A. (Ed.). Produção de sementes e mudas de espécies florestais. Lavras: UFLA, 2008. p. 11-82.

GIACHINI, R.M.et al. Influência da escarificação e da temperatura sobre a germinação de sementes de Samanea tubulosa (Benth.) BARNEBY ; J.W. GRIMES (sete cascas). Acta Amazônica, v.40, n.1, p.7580, 2010. acta.inpa.gov.br/redirect.php?volume $=40$; edicao $=1$

KISSMANN, C.et al. Tratamentos para quebra de dormência, temperaturas e substratos na germinação de Adenanthera pavonina L. Ciência e Agrotecnologia, v.32, n.2, p.668-674, 2008.

www.scielo.br/pdf/cagro/v32n2/51.pdf

LEAL, J.V. et al. Épocas de colheita e tratamentos pré-germinativos para superação da dormência de sementes de Mimosa caesalpiniifolia Benth. Revista Árvore, v.32, n.2, p.203-210, 2008.

www.scielo.br/pdf/rarv/v32n2/a02v32n2.pdf

LOPES, J.C.et al. Germinação de espécies florestais de Caesalpinea ferrea Mart. ex Tul. var. leiostachia Benth., Cassia grandis L. e Samanea saman Merril, após tratamentos para superar a dormência. Revista Brasileira de Sementes, v.20, n.1, p.80-86, 1998.

www.abrates.org.br/revista/artigos/1998/v20n1/artigo15.pdf

LOPES, J.C.; DIAS, P.C.; MACEDO, C.M.P. Tratamento para acelerar a germinação e reduzir a deterioração das sementes de Ormosia nitida Vog. Revista Árvore, v.30, n.2, p.171-177, 2006.

www.scielo.br/pdf/rarv/v30n2/a03v30n2.pdf

LORENZI, H. Árvores Brasileiras: manual de identificação e cultivo de plantas arbóreas nativas do Brasil. Nova Odessa: Plantarum, v.1, 1992. p.165-166.

MAGUIRE, J.D. Speed of germination-aid in selection and evaluation for seedlig emergence and vigor. Crop Science, v.2, n.1, p.176-177, 1962.

MARQUES, M.A. Secagem e armazenamento de sementes de Anadenanthera peregrina var. falcata (Benth.) Altschul e A. colubrina (Vell.) Brenan var. cebil (Griseb.) Altschul. 2007. 124 f. Tese (Doutorado em Agronomia) - Universidade Estadual Paulista, Jaboticabal.

MATHEUS, M.T.; DIAS, M.A.; LOPES, J.C. Termoterapia em sementes de guapuruvu (Schyzolobium parahyba (Vell.) Blake). Revista Brasileira de Biociências, v.5, n.2, p.330-332, 2007. Nota Científica. Disponível em: http://www6.ufrgs.br/seerbio/ojs/index.php/rbb/article/view/303/265 
NASCIMENTO, I.L. et al. Superação da dormência em sementes de faveira (Parkia platycephala Benth.). Revista Árvore, v.33, n.1, p.35-45, 2009. Disponível em:

http://www.scielo.br/pdf/rarv/v33n1/v33n1a05.pdf

PEREIRA, E.W.L.et al. Superação de dormência em sementes de jitirana (Merremia aegyptia L.). Revista Caatinga, v.20, n.2, p.59-62, 2007. Disponível em:

http://periodicos.ufersa.edu.br/revistas/index.php/sistema/article/view/312/113

PEREIRA, M.O.et al. Avaliação de métodos de escarificação na superação de dormência de Schizolobium parahyba (vell.) Blake (Fabaceae - Caesalpinioideae). Revista em Agronegócios e Meio Ambiente, v.4, n.1, p.119-129, 2011. Disponível em: www.sumarios.org/sites/default/files/pdfs/rama_v.4_n.1___07.pdf

ROBERTS, E.H. Predicting the storage life of seeds. Seed Science and Technology, v.1, n.2, p.499-514, 1973.

SMIDERLE, O.J.; MOURÃO JUNIOR, M.; SOUSA, R.C.P. Tratamentos pré-germinativos em sementes de acácia. Revista Brasileira de Sementes, v.27, n.1, p.78-85, 2005. Disponível em:

www.scielo.br/scielo.php?script=sci_nlinks; $r$ ref=000119.

SUÑÉ, A.D.; FRANKE, L.B. Superação de dormência e metodologias para testes de germinação em sementes de Trifolium riograndense Burkart e Desmanthus depressus Humb. Revista Brasileira de Sementes, v.28, n.3, p.29-36, 2006. Disponível em: http://www.scielo.br/pdf/rbs/v28n3/05.pdf 